\title{
Motor and verbal reaction times to words and drawings
}

PAUL FRAISSE, LABORATOIRE DE PSYCHOLOGIE EXPERIMENTALE ET COMPAREE DE LA SORBONNE, ASSOCIE AU CNRS, Paris, France

Verbal reaction time to drawings is always a little longer than verbal reaction time to words. In previous experiments this finding had been interpreted in terms of the greater uncertainty when naming a drawing than when reading $a$ word. In the present experiment, it is shown that the discriminability of the two categories of stimuli cannot explain the differences in VRT since the motor reaction time and the recognition threshold are a little higher for words than for drawings.

As a result of the work done by J. McK. Cattell, it is known that the time for naming (verbal reaction time) an object (or a color, a geometric figure, a drawing) is longer than the time for reading the name of that object. This result has been confirmed by Lund (1927), Ligon (1932), Fraisse (1964), but the explanation of this phenomenon is still disputed.

In attempting to explain the difference between the time for naming an object (object-naming) and the time for reading the corresponding name (word-reading), Brown (1915), Ligon (1932), Fraisse (1964) have studied the role of practice. However, it is to be noted that practice reduces but does not suppress the difference.

It is surprising that with young children who have just learned to read, word-naming is shorter than object-naming (Ligon, 1932). Fraisse (1964) has shown that when the number of objects to be named (uncertainty) increases, the verbal reaction time increases, whereas uncertainty has no influence on word-naming as Pierce \& Karlin (1957) and Conrad (1962) have stated. This result leads to the conclusion that S-R compatibility is high in word-naming, while it is low in object-naming. It is obvious that for a person who knows how to read there is only one verbal response to a written word, whereas several synonymous responses, at least a specific and a categorical one, may correspond to an object (Fraisse, 1965, Segui \& Fraisse, 1968). The increase of reaction time in object-naming would correspond to response uncertainty, a fact which confirms a general finding revealed by many authors (Pollack, 1959, Morin \& Forrin, 1963, Fraisse \& Voillaume, 1966).

However, this explanation remains unsatisfactory. Naming words and their corresponding objects leads to the same response, but two other variables play a role: the nature of the relations between $S$ and $R$ which we try to elucidate and the nature of the stimuli which are different: words and objects.

It is known that the relative discriminability of the stimuli has an influence on reaction time (Henmon, 1906) and the role of discriminability was confirmed in experiments on verbal reaction time (Fraisse, $1964 \mathrm{a}$, b). If objects were less discriminable than words, that alone would explain the higher reaction time in object-naming than in word-naming. We have already attempted to clear up the role of stimuli discriminability in a previous experiment with only one stimulus, namely a circle. This stimulus may be coded as object-naming (circle) in a set of geometric figures or as word-naming (letter $O$ ) in a set of letters. The results have shown that letter-naming is shorter than geometric figurenaming (Fraisse, 1967).

The purpose of the present experiment is to compare the discriminability of two sorts of stimuli, words and drawings, by using a motor reaction time procedure. It is hypothesized that discriminability of words and drawings is of the same order, in spite of the fact that verbal reaction time is longer for drawings than for their corresponding words. If the results support this hypothesis, then the difference in duration between word-naming and object-naming will be explained only by the higher uncertainty of response in object-naming than in word-naming.

Method

The $S$ is presented with the stimuli (words or drawings) in a three-channel tachistoscope (Scientific Prototype Model). He is instructed to press a key (which switches off the illumination of the stimulus) as soon as he has identified the stimulus and he is told that his identification will be checked, since he will have to name the stimulus.

It is hypothesized that the more difficult the discrimination of a stimulus, the longer the motor reaction time will be. This procedure allows to investigate the role of discriminability without using a verbal reaction.

Procedure

The experiment is run as follows. After the $S$ has been familiarized with the stimuli, there is a training period during which he has to give a verbal reaction and then a motor reaction to every stimulus.

The experiment proper includes four successive presentations of the list of all stimuli (words and drawings). The 30 stimuli in the list are randomized and there is a different ordering for each of the four presentations.

The $S$ gives verbal ard motor responses by turns; so there are two responses of each sort to every stimulus. The Ss are instructed to give the verbal or the motor responses as quickly as possible.

Materials

The stimuli were identical with that used in a previous experiment (Fraisse, 1964, p. 24) and consisted of: (1) Fifteen French words: five animal names: hen, rabbit, sheep, duck, pig; five plant names: tree, mushroom, leaf, grape, leek: five object names: key, lamp, violin, scissors, chair. The words were written in capital letters (Letraset) $(4.2 \mathrm{~mm}$ high and $0.5 \mathrm{~mm}$ wide). (2) Fifteen shaded drawings corresponding to the 15 words made in India Ink within the borders of a $5 \mathrm{~cm}$ square on a side; the characteristics details were pregnant. Ten psychology students participated in the experiment.

Results

An analysis of variance on the data revealed, as expected, a very important difference between MRT and VRT. There is also a significant difference at the ,005 level between VRT to words and to drawings. The results are in the same direction for all Ss and for the 15 pairs of drawings and words.

There is a slightly significant difference between MRT to drawings and words at the .10 level. MRT and VRT are in opposite directions: MRT to words is a little longer than MRT to drawings (mean difference: $10 \mathrm{msec}$ ). This is true for 7 of the $10 \mathrm{Ss}$ and for 12 of the 15 pairs of drawings and words. It has been hypothesized that there would not be any difference between MRT to words and drawings, but the analysis of the results shows that words are a little less descriminable than drawings, at least with the type of materials we used.

There is evidently a very significant interaction between MRT and VRT on one hand, and drawings and words on the other hand, since the differences are in opposite directions.

A correlation $(\rho=.50)$ has been found between familiarity of the words (rated on a 3 category response scale by 100 students) and VRT to the same words; the correlation between familiarity of the words and VRT to the drawings is also $p=.50$. There are rather negative correlations with MRT. This result is in accordance with the interaction which has already been pointed out. Conclusion

The recognition, measured by MRT, is as rapid for drawings as for words, and could even be faster for drawings than for words.

Table 1

\begin{tabular}{|c|c|c|}
\hline & $\begin{array}{c}\text { Motor reaction time } \\
\text { MRT }\end{array}$ & $\begin{array}{c}\text { Verbal reaction time } \\
\text { VRT }\end{array}$ \\
\hline drawings & $\begin{array}{c}249 \mathrm{msec} \\
\sigma=54,1^{*}\end{array}$ & $\begin{array}{l}563 \mathrm{msec} \\
\sigma=78,8\end{array}$ \\
\hline words & $\begin{array}{l}259 \mathrm{msec} \\
\sigma=65,3\end{array}$ & $\begin{array}{l}473 \mathrm{msec} \\
\sigma=48,1\end{array}$ \\
\hline
\end{tabular}

* Mean of intra-individual standard deviations (on 30 responses). 
This result has been tested by using another procedure, with two different groups of $S s\left(N_{1}=20 ; N_{2}=25\right)$ and with the same stimuli. Recognition thresholds for the 15 words and the 15 drawings have been measured by the method of ascending limits. All stimuli were presented at every duration, in a random order, until they were all recognized. The mean threshold for drawings and words was respectively 21.5 and $24.8 \mathrm{msec}$. The difference is in the same direction as that of the MRT, but it is not significant. It suggests that word recognition would be a little more difficult than drawing recognition in our situation.

The fact that VRT is higher with drawings than with words cannot be explained by the smaller discriminability of drawings. Thus, it can be stated that the longer VRT to drawings are explained by the greater difficulty for finding the adequate response to the drawing. More precisely, it can be said that uncertainty in the coding process is higher with drawings than with words. This conclusion is probably to be generalized to other concrete materials (objects, geometric figures, colors) since the same phenomenon has been found with all those types of materials.

Thery is no significant difference in the duration of the detection process (receipt, discrimination and identification) of a concrete or verbal material, but the coding of the verbal response to a concrete stimulus is more difficult than the coding of the verbal response to a written verbal stimulus.

\section{REFERENCES}

BROWN, W. Practice in associating color names with colors. Psychol. Rev. $1915,22,45-55$.
CONRAD, R. Practice, familiarity and reading rate for words and nonsense syllables Quart. J. exp. Psychol, 1955, 7, 176-195.

FRAISSE, P. Le temps de réaction verbale. I. Dénomination et lecture. Année Psychol, 1964a, 64, 21-46.

FRAISSE, $P$. Relations entre le seuil de reconnaissance perceptive et le temps de réaction verbale. Psychol Franc., 1964b, 9, 77-85.

FRAISSE, P. Le role de l'incertitude et de la discriminabilité dans la reconnaissance perceptive. Année Psychol, 1967, 67, 61-72.

FRAISSE, P., \& VOILLAUME, C. Incertitude du stimulus et incertitude de la réponse dans la reconnaissance perceptive. Annee Psychol, 1966, 66, 397416.

FRAISSE, P., LANATI, L., REGNIER, J., \& WAHL, M. Le temíps de réaction verbale. II. Reponses specifiques et catégorielles. Annee Psychol, 1965, 65, 27-32.

HENMON, V. A. C. The time of perception as a measure of differences in sensations, Arch Philos. Ps. Sci. Meth N. Y., 1906, 8.

LIGON, E. M. A genetic study of color naming and word naming. Amer. J. Psychol, 1932, 44, 103-110.

LUND, F. H. The role of practice in speed of association. J. exp. Psychol, $1927,10,424-433$.

MORIN, R. E., \& FORRIN, B. Response equivocation and reaction time. $J$. exp. Psychol, 1963, 66, 30-36.

PIERCE, J. R., \& KARLIN, J. E. Reading rates and the information rate of a human channel. Bell. Syst. Tech. J., 1957, 36, 497-516.

POLLACK, I. Message uncertainty and message reception. J. Acoust. Soc. Amer., 1959, 31, 1500-1508.

SEGUI, J., \& FRAISSE, P. Le temps de réaction verbale. Réponses spécifiques et reponses catégorielles a des stimulus objets. Année Psychol, 1968,68 , in press. 